\title{
La Fuerza Masculina y la Fuerza Animal: Construcciones Identitarias en torno a la Migración Laboral de Trabajadores Forestales en Argentina
}

\author{
Male Force and Animal Force: Identity Constructions around \\ Labor Migration of Forestal Workers in Argentina
}

Alfonsina Verónica Alberti ${ }^{\mathrm{I}}$

\begin{abstract}
RESUMEN
El presente articulo trata sobre los peones forestales del nordeste de Misiones, que se desplazan hacia los bosques cultivados de Eucaliptos, situados en las provincias de Corrientes y Entre Rios, en donde son contratados por plantaciones eslabonadas a la industria celulósica y maderera, para actividades de cosecha. Especificamente nos interesa dar cuenta de aquellos elementos identitarios que se ponen en juego en la producción de discursos que conciben a los trabajadores misioneros como idóneos para realizar las tareas productivas implicadas en este tipo de migración laboral. Teniendo en cuenta que todo proceso identitario es el resultado de una interacción relacional, se pondrá atención tanto a la visión que poseen los trabajadores sobre si mismos, como a la manera en que éstos son representados por sus empleadores. A su vez, se buscará dar cuenta de qué forma estos procesos identitarios funcionan justificando la precariedad laboral presente en este tipo de trabajo. De esta manera, se verá la relevancia que tienen las categorías culturales en el proceso de construcción de un mercado laboral segmentado en el cual la condición de migrante implica ocupar los puestos menos valorizados del sector.

Palabras Clave: Migración Laboral, Actividad Forestal, Precarización Laboral, Identidades Sociales, Argentina.
\end{abstract}

\section{Abstract}

This article is about forest roustabouts/laborers from Northeast Misiones that go to cultivated eucaliptus forests, set in the Provinces of Corrientes and Entre Rios, where they are hired by plantations deboted to celuloid 
and wood industry for harvesting activities. We are particularly interested in becoming aware of those identity elements that are put at stake in the discouse production that consider workers from Misiones as capable of doing productive labor involved in this type of labor migration. Taking into account that every identity process is the result of a relation interaction,we will focus on both the labourers self-image and the way they are represented by therir employers. At the same time, we will try to show the way these identity processes work justifying the labour precoriousness present in this kind of labor. Thus, you will see the relevance of cultural categories in the process of building a segmented labor market in which migrant status means less valued occupy positions in the sector.

Key words: Labour Migration, Forest Activity, Labour Precariousness, Social Identities, Argentina

\section{INTRODUCCIÓN}

Los desplazamientos temporales de trabajadores rurales, en América Latina, constituyen un patrón histórico que se inicia en el siglo XIX con el surgimiento del trabajo asalariado, vinculado con las demandas de zafra y cosecha en las explotaciones agrícolas capitalistas (Bendini et al. 2012). En la actualidad el fenómeno no sólo ha persistido sino que se ha incrementado y ha adquirido nuevos significados a la luz de los contextos de reestructuración productiva del agro (Neiman 2010).

En relación con este fenómeno, nuestro artículo versa sobre migraciones laborales temporarias, es decir desplazamientos de trabajadores que no conllevan un cambio de residencia permanente. Específicamente, nos interesa indagar sobre cuáles son las características identitarias que se les asignan a los trabajadores migrantes estudiados, para crear un estereotipo que los conceptualiza como idóneos para la realización de ciertas tareas productivas. El estudio ha sido realizado en dos provincias de la Argentina, Misiones y Entre Ríos, siendo la primera el lugar de procedencia de los trabajadores y la segunda uno de los sitios al cual los mismos se dirigen a trabajar en la fase de cosecha de la actividad forestal. En este contexto, la movilidad implica la participación en un mercado de trabajo en el cual la condición de migrante agudiza la relación asimétrica existente entre empleadores y trabajadores. Es por ello, que nos interesa poner en relieve las características que asumen las interacciones entre los actores que participan en este mercado, y que resultan relevantes para comprender su funcionamiento. Para ellos centraremos nuestra atención 
en las categorías culturales que se ponen en juego a la hora de identificar a los trabajadores estudiados.

A su vez, la migración laboral que analizamos puede enmarcarse dentro de lo que la sociología ha denominado como "Mercado de trabajo segmentado"; según esta perspectiva, el mercado de trabajo se encontraría dividido en dos segmentos, uno primario y otro secundario. El primero ofrece puestos de trabajo con salarios relativamente elevados, buenas condiciones de trabajo y estabilidad de empleo, el segundo tiende a estar peor pagado, a tener condiciones laborales peores, a tener una relación muy personalizada entre supervisores y trabajadores, lo cual lleva a una disciplina laboral dura y caprichosa; y a estar caracterizados por una considerable inestabilidad de empleo y una elevada rotación de la población trabajadora (Piore 1983).

De acuerdo con el enfoque arriba mencionado, los trabajadores de origen migratorio van a ocupar los puestos de trabajo en los que los trabajadores locales no están dispuestos a ocuparse porque los colocan en una posición social baja y sin posibilidades de movilidad social (Neiman 2009). De este modo esta perspectiva pone en tela de juicio la libertad de la movilidad de la mano de obra en el libre juego de la oferta y la demanda, conceptualizado por la economía neoclásica, debido a que estos mercados laborales estarían pensados para la inserción de ciertos segmentos de la población, especialmente aquellos que por diversos motivos se encontrarían en situaciones de vulnerabilidad que pondrían en peligro su subsistencia (minorías étnicas, mujeres, trabajadores foráneos; Lara Flores 2001).

Siguiendo a Mingo (2006), el enfoque de la segmentación parte de interpretar que para comprender el funcionamiento de los mercados de trabajo es necesario incluir los patrones culturales, sociales y de dominación presentes en la estructura social. A diferencia de las interpretaciones de la teoría neoclásica en las que se considera al mercado de trabajo como un espacio homogéneo que debe ser interpretado desde una matriz netamente económica, esta perspectiva reconoce la heterogeneidad en el funcionamiento de los mercados de trabajo.

En relación a estos procesos, Wolf (1993) sostiene que las clasificaciones que diferencian a la fuerza de trabajo y que asignan a ciertos trabajadores a determinadas posiciones laborales y a otros trabajadores a otras en virtud de sus características culturales o fenotípicas, dan forma a una segmentación étnica del mercado de trabajo que resulta funcional a la actual modalidad de acumulación del capital. 
Por otro lado, Giarracca (2000), refiriéndose a las características de los mercados rurales en la Argentina, afirma que las transformaciones que ocurren en estos, incluyendo los procesos de segmentación, no son cambios estructurales despersonalizados, sino que implican interacciones, conflictos y negociaciones entre los diversos actores.

Para el caso de la Argentina, varios estudios abordan el problema de la segmentación en el mercado de trabajo en relación a los estereotipos que se le adjudican a los trabajadores migrantes, y a través de los cuales se justifican situaciones de precarización laboral (Archentti y Tomas 1997, Margulis 1998, Benencia 2002, Pizarro et al. 2011). Es importante aclarar que, con excepción del trabajo de Margulis (1988), el resto aborda el problema desde los desplazamientos internacionales, y en todos los casos se trata de migraciones con cambio de residencia.

Por otra parte, en relación a las migraciones laborales de tipo temporal, una de las dificultades que han presentado los estudios ha sido la falta de datos que permitan cuantificar el fenómeno. Al respecto, Tadeo y Palacios (2005) advierten que es conocida la dificultad para captar movimientos espaciales de población por la ausencia o insuficiencia de datos en los relevamientos censales; no obstante los estudios de caso a escala micro, aportan al conocimiento para dimensionar los procesos migratorios y su incidencia social desde una perspectiva temporal, por la significación que adquieren en el origen y en el arribo, y no solo por la cantidad de personas que interviene en el desplazamiento.

De este modo, en relación con el enfoque desarrollado, los elementos que en nuestro caso de estudio nos permiten identificar la segmentación laboral son: i) la movilidad de los trabajadores no es una elección libre sino que es organizada por los contratistas y es producto de la falta de oportunidades laborales en su región de origen; ii) no hay un dispositivo autorregulado que organice el contacto entre la oferta y la demanda, esta interacción depende de redes sociales que difunden la información y pueden estar conformadas por vínculos de amistad, vecindad y parentesco; iii) las actividades de la fase de cosecha en la que se desempeñan los trabajadores migrantes que analizamos son las peor remuneradas (pago a destajo) e implican las peores condiciones laborales del sector forestal. Esta situación implica reconocer que los trabajadores estudiados ocupan puestos de trabajo que les son asignados de antemano por su condición de migrantes, siendo los puestos mejor valorizados, con respecto a la remuneración y a las condiciones laborales, destinados a trabajadores locales. 


\section{Material Y MÉtodo}

El abordaje metodológico ha sido principalmente cualitativo y ha estado orientado a partir de la denominada "perspectiva del actor", que es una construcción orientada teóricamente por el investigador, quien busca dar cuenta del contexto significativo en el que conducen sus vidas los sujetos sociales en cuestión (Guber 1991). La investigación cualitativa se ha reconocido particularmente apta para plantear dos tipos de preguntas: (a) sobre el significado de los eventos y actividades para las personas que están involucradas en los mismos y (b) acerca de la influencia del contexto (económico, social, político) sobre esos eventos y actividades (Maxwell 1996). Por ello, un aspecto central de esta estrategia tiene que ver con la necesidad de comprender desde la perspectiva de los propios actores, reconociendo los significados que éstos dan a su acción y a la de los otros, aunque siempre en un contexto que es estructurado y a la vez estructurante de ese mundo. En este sentido, la "entrevista personal" se constituirá en el procedimiento central para recolectar información a fin de lograr una descripción de acciones, procesos y eventos.

A su vez, el trabajo de campo estuvo dividido en tres etapas. Una primera etapa se realizó en junio del 2010 en la provincia de Entre Ríos, donde pudimos acceder al campamento forestal de una gran empresa en las inmediaciones de Concordia y luego al campamento de un mediano productor. En esta instancia realizamos un total de 17 entrevistas en profundidad, a trabajadores, contratistas y patrones, orientadas a la obtención de información sobre las condiciones de vida y trabajo en los campamentos forestales Las entrevistas a los trabajadores se encontraban condicionadas debido a que se desarrollaron en el ámbito laboral, cerca de sus empleadores, por lo cual el objetivo principal de las mismas fue averiguar la localización de los hogares de procedencia en Misiones, para posteriormente allí contactarlos. La técnica de la entrevista estuvo complementada por la observación de las condiciones de trabajo en los campamentos. La información más valiosa obtenida surgió de las entrevistas a los empleadores, quienes proporcionaron datos en torno a la visión que tenían de los trabajadores migrantes. 


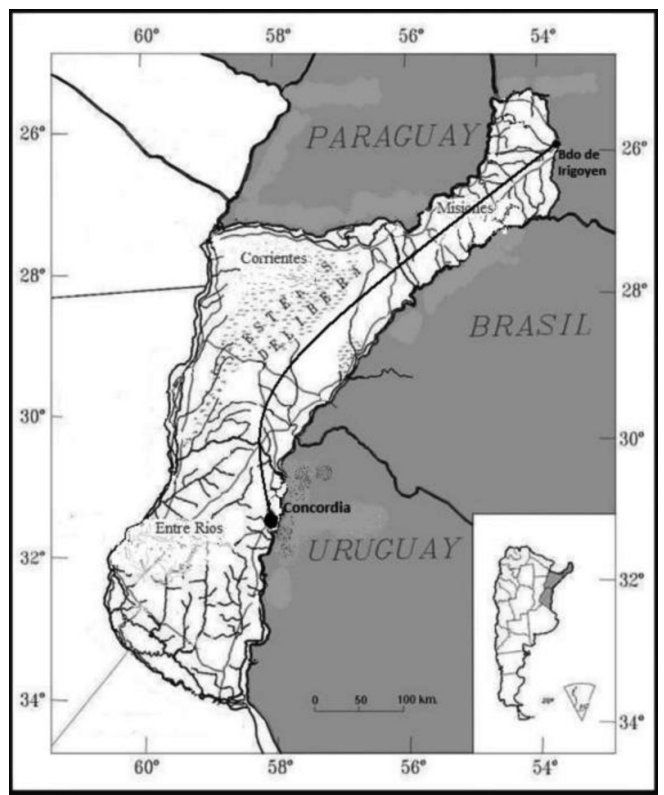

Figura 1: Lugares de procedencia y de destino de los trabajadores migrantes.

Figure 1: Places of origin and destination of migrante workers.

La segunda etapa se efectuó en la provincia de Misiones en diciembre del 2011. Allí realizamos 18 entrevistas en profundidad a los trabajadores y a los miembros de sus familias, en el contexto de sus hogares; las mismas estuvieron orientadas a recabar información en torno a la percepción que tenían los trabajadores y sus familiares sobre las condiciones de vida y trabajo en los campamentos forestales. Los hogares se encontraban emplazados en varios parajes rurales ubicados a la zona de Bernardo de Irigoyen (Departamento General Belgrano). A través de ella, dimos cuenta del perfil sociodemográfico de los trabajadores (hombres jóvenes, con baja escolarización), caracterizamos a los distintos tipos de hogares (según: tamaño, composición, balance de género y generación) y sus estrategias de reproducción social.

Por último, durante diciembre del 2012, mediante la técnica llamada "bola de nieve" localizamos 15 hogares más en la zona de origen de los trabajadores. Mediante la implementación de entrevistas a trabajadores migrantes, ex trabajadores migrantes y familiares de migrantes, el objetivo de esta etapa consistió en profundizar la información obtenida anteriormente en cuanto a la visión que tenían los trabajadores de la migración laboral y captar una diversidad mayor de tipos de hogares (hogares compuestos por familias extensas, hogares compuestos por familias nucleares, hogares con predio para autoconsumo, hogares sin predio). 
No obstante el sesgo cualitativo presente en este trabajo, también se han utilizando fuentes de información secundaria como son los informes gubernamentales, los censos y los textos académicos para conocer y describir algunas características socioeconómicas propias de la región NE de Misiones; como así también cuestiones vinculadas a la actividad forestal en la cual se desempeñan los trabajadores misioneros, con el fin de comprender cuál es el contexto en el que se generan este tipo de migraciones, y a la luz del cual cobran sentido las distintas prácticas y representaciones desplegadas por los actores.

\section{Contexto y CARACTERÍsticas DE LA MIGRACIÓN ESTUDIADA}

La explotación intensiva del bosque nativo acompañó el poblamiento y la expansión de la frontera agrícola en la provincia de Misiones. A mediados del siglo XX, en un contexto de diversificación productiva y bajo el estímulo de un mercado demandante (exportación de celulosa) y leyes específicas de promoción, comienza la forestación con especies exóticas en algunas áreas de la provincia.

Sin embargo, en las dos últimas décadas, se modificaron las condiciones del empleo forestal, especialmente en la zona de mayor dinamismo y desarrollo celulósico-papelero y maderero (noroeste). A partir de 1996, el traspaso a un grupo chileno del principal empleador (Alto Paraná S.A.), profundizó el proceso de tercerización, característico de la actividad, afectando a los hacheros y motosierristas ${ }^{1}$. La mecanización del corte (introducción de procesadoras), las exigencias de seguridad y la categorización de las tareas fueron los principales elementos del cambio.

A su vez, desde mediados de la década de 1980, las grandes propiedades de explotación de monte nativo del nordeste provincial (ubicadas en la zona de General Belgrano, en donde se emplazan los hogares de procedencia de los trabajadores estudiados) experimentaron un proceso de crisis que se tradujo en la quiebra de las empresas y el despido de los obreros.

En estos latifundios extractivistas del nordeste de Misiones en donde se encuentran los hogares de procedencia de los migrantes estudiados, una vez explotado el monte, la tierra es abandonada sin que se generen condiciones para su posterior utilización. La tenencia precaria sujetó a los trabajadores a la tierra, convirtiendo la zona en un área de reserva de mano de obra, a la que acuden los contratistas para 'llevar gente' a Entre Ríos y Corrientes (Schiavoni 2010). 
Con los datos sobre distribución de la tierra y equipamiento productivo del Censo de Ocupantes de Tierras Privadas de Misiones 2003-2004, Baranguer y Schiavoni (2005) muestran que más del 30\% de la población de ocupantes, en cada una de estas grandes propiedades, está asentada en parcelas de hasta 10 ha. Asimismo, cerca del $40 \%$ y más de los ocupantes no dispone de equipamiento productivo. Estos elementos sugieren que se trata de una población dedicada sólo parcialmente a la agricultura, presumiblemente vinculada al trabajo forestal temporario.

Por otro lado en el departamento de Concordia, Entre Ríos, a fines de la década de 1970, en virtud de un sistema de desgravación impositiva, se plantaron 60.000 hectáreas de eucaliptos. En una "zona netamente citrícola y ganadera", "la actividad forestal estaba totalmente descolgada y originó también que no haya mano de obra de esa índole" (contratista).

En Entre Ríos la superficie cultivada abarca cerca de $130 \mathrm{mil}$ hectáreas (Dirección de forestación SAGP, y A 2010). La producción forestal se concentra en los departamentos de Colón, Concordia y Federación, al nordeste de la provincia (junto con el sudeste de la provincia de Corrientes conforman la Cuenca Forestal del Río Uruguay) y, en el sur, en Islas del Ibicuy.

La implementación forestal se desarrolla predominantemente en explotaciones medias (de 100 a 500 hectáreas) y en grandes (más de 500) en los departamentos de Colón y Concordia. Mientras que prevalece en unidades más pequeñas (entre 100 y 50 hectáreas) en Federación.

Se inicia así una actividad sin antecedentes en la región que requirió la conformación de un mercado de trabajo y la presencia de empresas procesadoras de la materia prima. Los grandes volúmenes de madera destinada a la exportación demandaban importante cantidad de mano de obra conocedora de las tareas del obraje y dispuesta a realizar el trabajo bajo condiciones precarias. La provincia de Misiones exhibía ventajas por la antigüedad en la actividad forestal extractiva y la existencia de contratistas que efectuaban servicios forestales a grandes empresas.

El proceso de expansión forestal en Entre Ríos estuvo acompañado por la radicación de aserraderos de pequeña y mediana escala en las proximidades de las ciudades de Concordia y Federación, y en la localidad de Ubajay. Durante la primera mitad de la década de 1990, estos aserraderos invierten en maquinarias y se produce una integración hacia adelante de las empresas forestales (Vera et al. 2009). En 1995, se suma la instalación de 
una gran planta industrial (Masisa) orientada a la producción de tableros de partículas y de fibra.

Los trabajadores misioneros se insertan en este mercado laboral, a través de la migración temporaria para realizar tareas vinculadas con la cosecha (apeo y extracción), sin radicarse definitivamente en la región. Mientras tanto, las tareas relacionadas con la plantación y la post cosecha son realizadas principalmente por mano de obra local (Bardomas y Díaz 2007).

Si bien a través de los años se incorporaron algunos trabajadores locales, los informantes clave consultados estiman que entre el 70 y el $80 \%$ de la mano de obra ocupada en las plantaciones de Entre Ríos procede de Misiones (Schiavoni et al. 2012).

Las tareas realizadas son el pelado o raleo con machete, el corte de árboles con motosierra y la carga de madera con máquinas. Los productos elaborados son vigas, postes, tijeras, rodrigones ${ }^{2}$. El pago por el trabajo es a destajo, es decir se paga la cantidad de producto elaborado, lo cual estimula un ritmo de trabajo muy exigente para los migrantes, quienes buscan maximizar el rendimiento trabajando por jornadas que se prolongan hasta diez horas diarias. A esta situación se suma la pérdida de ganancia por días de lluvia en los cuales no es posible trabajar.

El carácter temporario de la migración en forestación no está condicionado por una estacionalidad ligada a los ciclos naturales, sino al hecho de que las forestaciones son plantaciones manejadas y el momento de realización de estas prácticas depende en gran medida del plan de gestión (Bardomas y Díaz 2007). Por lo general los trabajadores suelen quedarse entre 35 y 40 días en sus lugares de trabajo y regresan a sus hogares durante períodos de no más de 10 días, con lo cual pasan la mayor parte de su tiempo fuera de sus lugares de procedencia.

En todos los casos intervienen contratistas para reclutar la mano de obra en Misiones. Si bien en las explotaciones pequeñas y medianas puede haber un trato cara a cara con el patrón (dueño del monte), es el contratista quien se encarga de reclutar a la gente en origen, además, este sujeto es el que tiene la función de controlar el trabajo en los campamentos y brindar los alimentos y bebidas a los trabajadores.

Por otra parte, las condiciones laborales del trabajador forestal son consideradas mundialmente de las peores no sólo en el medio rural sino en el conjunto de las actividades económicas. La OIT considera que la forestación 
-junto con la construcción y la minería- es de los sectores de actividad más riesgosos por la alta incidencia de accidentes laborales y de siniestros mortales (OIT 1997). A las malas condiciones de trabajo se suma la precariedad en la que el trabajador debe vivir en el monte; esto lleva a que la actividad sea poco atractiva para la mano de obra local, a la gran rotación de la misma y a su escasa especialización (Bardomas y Díaz 2007).

\section{AlgunOS CONCEPTOS TEÓRICOS PREVIOS AL ANÁLISIS: IDENTIDAD SOCIAL, ESTEREOTIPO Y MASCULINIDAD}

En relación al argumento expuesto en nuestra introducción, sostenemos que es importante comprender aquellos elementos culturales que se ponen en juego en la interacción social para comprender la segmentación del mercado laboral. Por ello, en primer lugar desarrollaremos algunos aspectos teóricos en torno a las nociones de Identidad social, estereotipo y masculinidad, pertinentes para el posterior abordaje de los discursos emitidos por los distintos actores partícipes de la migración laboral sobre la cual versa este artículo.

Cuando hacemos referencia al concepto de Identidad, traemos a colación el desarrollo teórico iniciado por Frederik Barth (1976) quien ha sido considerado el pionero en la conceptualización de la identidad como manifestación relacional a partir de la interacción social, superando así planteos subjetivistas y objetivistas ${ }^{3}$. A su vez las identidades deben ser concebidas en vinculación con las relaciones de poder. En este sentido, Giménez (1994) propone que la identidad de un actor emerge y se afirma solo en la confrontación con otras identidades en el proceso de interacción social, la cual frecuentemente implica relaciones desiguales y, por ende, luchas y confrontaciones.

De esta manera podemos afirmar que la identidad es una ecuación resultado de la interacción entre dos polos: un nosotros y un los otros. Al respecto Sinisi (1998) define dicha relación de la siguiente manera: cada uno de nosotros construimos un "yo" que se identifica con un colectivo "nosotros" que a su vez se contrasta con algún "otro". El otro puede aparecer distante y benigno, puede ser muy cercano y cotidiano o distante pero peligroso, generando un sentimiento de amenaza e inseguridad.

El sentimiento de amenaza refuerza la construcción de un nosotros alejado del otro. Una forma de alejamiento sería la construcción de estereotipos. Para Perrot y Preiswerk (1983) el estereotipo se compone de 
dos elementos: la simplificación y la generalización. A través del primero, la realidad es simplificada en la elección de elementos específicos, omisiones concientes y olvidos. Por la generalización una misma categoría es definida según un grupo de conceptos, sin reflexionar sobre las excepciones, cuando se ha visto a uno a se ha visto a todos.

Otro aspecto que resulta importante destacar, es la relación que se ha planteado entre identidad y discurso, al respecto Hall y Du Gay (2003) ponen el acento en el discurso como elemento que organiza toda la vida social y consideran que las identidades se construyen dentro del discurso y no fuera de él. Necesitamos entenderlas como producidas en lugares históricos e instituciones específicas, en formaciones discursivas y prácticas particulares, a través de estrategias enunciativas concretas.

De este modo el discurso puede ser conceptualizado como práctica social. En este sentido Pizarro (2012), retomando a Hanks (2005) y a Briggs (2005), plantea cómo la clasificación de lo social a través del lenguaje naturaliza las relaciones de fuerza que operan en la construcción de dicha clasificación. Siendo posible, de esta manera, detectar a través del análisis conversacional, los estereotipos raciales que emergen en el plano discursivo e influencian diversos espacios sociales.

A su vez, las identidades pueden funcionar un conjunto de sistemas clasificatorios que tienen por finalidad distinguir a los miembros del propio grupo de quienes no lo son. De esta manera, cada sujeto pertenecerá de forma simultánea a varios sistemas clasificatorios -según el referente sea etnia, clase, género, edad, religión, etc.- que de acuerdo al contexto se actualizarán priorizando uno u otro eje (Archenti 2008).

En este sentido, el género será un componente importante para la auto identificación de estos trabajadores, ya que el mismo emergerá como eje central en explicación que dan los misioneros de sí mismos como aptos para realizar el trabajo forestal.

El género, además, puede ser entendido como intensidad, esto quiere decir, puede ser una cualidad que se asume con mayor o menor intensidad, por ejemplo en la infancia suele considerarse que los nińos son masculinos con menor intensidad que en la edad adulta. La Cecla (2005), retomando ideas de Mauss (1936), indica que "para la identidad sexual se puede hacer un discurso análogo: soy una condición (masculina o femenina) que se convierte en una "facultad", una "capacidad" de estar tan a gusto dentro de mi propio cuerpo, sentido como masculino o femenino, que me hace olvidar todo el proceso de adquisición y aprendizaje (forzoso o voluntario) que hay detrás" (La Cecla 2005:17). 
Por último debemos señalar que las nociones de identidad, género y estereotipo, deben ser articuladas con la dinámica de clases sociales. En este sentido resulta útil la noción de "racialización de las relaciones de clase" elaborada por Margulis (1998); la misma hace referencia a los mecanismos mediante los cuales la restricción desigual del acceso a los capitales (económico, cultural, educativo, social) se justifica en principios racistas de prejuicios basados en criterios de selección inapropiados para el ámbito en cuestión.

\section{IDENTIDADES EN EL PROCESO DE LA MIGRACIÓN}

LABORAL HACIA LA ACTIVIDAD FORESTAL:

“LA FUERZA MASCULINA" Y "LA FUERZA ANIMAL"

En la obra literaria del escritor Horacio Quiroga podemos encontrar algunas pistas para comprender cómo durante el siglo XIX se iba configurando una mirada despreciativa en torno a los peones rurales misioneros, la cual legitimaba las nefastas condiciones de trabajo que reinaban en los obrajes:

"Cayetano Maidana y Esteban Podeley, peones de obraje, volvian a Posadas en el Silex con quince compañeros. Podeley, labrador de madera, tornaba a los nueve meses, la contrata concluida y con pasaje gratis por lo tanto. Cayé -mensualero- llegaba en iguales condiciones, mas al año y medio, tiempo que habia necesitado para cancelar su cuenta (..). Flacos, despeinados, en calzoncillos, la camisa abierta en varios tajos, descalzos como la mayoría, sucios como todos ellos, los dos mensú devoraban con los ojos la capital del bosque. ¡Nueve meses allá arriba! jAl año y medio" (Horacio Quiroga: 1971).

Los trabajadores a los que hace alusión el fragmento literario aquí citado han sido denominados tradicionalmente como los "Mensú". Las actuales migraciones laborales de hombres misioneros hacia la actividad forestal en las provincias de Corrientes y Entre Ríos dan cuenta de cómo se reactualizan los estereotipos ${ }^{5}$ que han sido utilizados históricamente para conceptualizar a estos trabajadores, y que funcionan como legitimadores de situaciones de tratos discriminatorios dentro de la esfera laboral. A lo largo de la mencionada obra de Quiroga, puede apreciarse cómo estos trabajadores eran caracterizados, como sucios, adeptos a las bebidas alcohólicas, irresponsables y de modales brutos, lo cual en algunas ocasiones aparecía relacionado a sus orígenes étnicos. En relación con esto, veremos cómo en la actualidad los patrones y contratistas siguen caracterizando a los trabajadores 
misioneros a través de adjetivos peyorativos que naturalizan situaciones de precarización laboral.

En relación con esto, nos interesa centrarnos en el juego de los procesos de heteroidentificación y autoidentificación ${ }^{6}$, que coloca al misionero como “apto" a la hora de desempeñarse como trabajador forestal a través de las migraciones extra provinciales. De esta manera el análisis estará estructurado a partir de la siguiente pregunta: ¿Cuáles son aquellos elementos identitarios implicados en la construcción de un discurso que concibe al misionero como "buen trabajador forestal"? La respuesta a esta pregunta será abordada, por un lado, desde las explicaciones otorgadas por los trabajadores, y por otro lado, desde las explicaciones que brindan contratistas y patrones.

En el transcurso de nuestro trabajo de campo, hemos tenido la oportunidad de ingresar a dos tipos de lugares de trabajo, uno de ellos fue el campamento de una gran empresa ubicada en las inmediaciones de Concordia y el otro fue un campamento perteneciente a un mediano productor, dueño de unas 200 hectáreas de monte para reforestación a pocos kilómetros de la ciudad de Concordia.

En el primero de los casos, hemos observado las condiciones laborales altamente precarizadas en las que se encontraban los trabajadores, una serie de containers hacían de habitaciones colectivas en donde hasta 10 personas dormían, un solo baño en pésimas condiciones era utilizado por más de 30 personas, también cabe señalar que el campamento se encontraba alejado a más de $10 \mathrm{Km}$. de la ciudad de Concordia, esto sumado al hecho de que en el monte la seńal telefónica es muy mala, contribuía al aislamiento de los trabajadores.

En el momento en que el contratista que nos había habilitado la entrada al campamento, percibió que estábamos observando una situación que nos resultaba sorprendente, empezó a explicar que en realidad él ya había introducido algunas mejoras para que los trabajadores se encuentren más cómodos, pero que las mismas no servían de nada. En palabras del contratista: “(.) Porque estos tipos no están acostumbrados, rompen todo, como allá viven asi nomás, no tiene sentido arreglar demasiado, no lo pueden aprovechar".

De esta manera la situación de pobreza en los hogares de procedencia de los trabajadores, es naturalizada como algo a lo que ellos están acostumbrados, funcionando la misma como justificación para no mejorar las condiciones habitacionales de los campamentos. 
En el campamento forestal del mediano productor, observamos que las condiciones laborales eran aún más precarias que las existentes en la empresa que habíamos visitado anteriormente; los trabajadores se alojaban en casillas de madera, no contaban con bańos y no tenían indumentaria adecuada para desempeñarse en el trabajo, no poseían cascos ni calzado adecuados, para protegerse de accidentes laborales.

La naturalización de estas pésimas condiciones laborales a las que son sometidos los migrantes debe comprenderse en relación a la manera en que estos son conceptualizados por sus empleadores. Una de las formas de acceder a la identificación de los trabajadores por parte de los empleadores es a través de la explicación que brindan los segundos sobre las cualidades idóneas para el trabajo forestal de los primeros.

En lo que respecta a la manera en que los empleadores conciben a los migrantes, debemos señalar que la categoría de animal y la categoría de indio parecerían términos intercambiables, de manera que la etnicidad aparecería como una condición otorgada por la naturaleza, convirtiendo al trabajador en un otro tan lejano que ni siquiera es reconocido como ser humano. Al respecto el testimonio de un mediano productor forestal afirma que:

"Son como animales, y pasa que son indios, la otra vez me enteré que uno abandonó a la hija, la dejó con un vecino, 6 o 7 años tendría la chiquita, y el tipo se vino a enterar de que estos vecinos habian abusado sexualmente de la nena, yo no entiendo a esta gente, tira a los hijos, ahora le dije que vaya para allá y mate al tipo que le hizo eso a su hija, yo no entiendo a esta gente, y es así, es la naturaleza".

A su vez, esta esencia animal, relacionada a una ascendencia aborigen se vincularía con el desarrollo de aptitudes físicas idóneas para el trabajo en el monte:

"El tipo que no sirve para esto enseguida empieza con las quejas de que le duele la cintura, que le dio un tirón, que quiere ir al médico; en cambio los que saben hacer bien el trabajo por ahi les duele algo pero ni le dan bolilla, capaz que si se corta un dedo se lo orina y sigue trabajando. Porque no le da importancia a esas cosas y quiere producir y quiere ganar, el tipo que sirve para esto es fuerte".

Estas identificaciones del otro como animal, como indio, como natural, también lo colocan como poseedor de una fuerza "diferente", "Al estar adaptados al monte, para ellos esto no es muy pesado", comentaba otro 
contratista entrerriano. Este atributo de "fuerza" se desprende del atributo de "animalidad". De esta manera queda al descubierto cómo este discurso de la alteridad construido desde la diferencia contribuye a la legitimación y reproducción de la precarización laboral, a la que se encuentran sometidos estos trabajadores.

Ahora pasemos al proceso de autoidentificación de los misioneros en tanto que trabajadores forestales. Estos actores, a la hora de explicar por qué eran contratados para desempeñarse en la actividad forestal, resaltaban dos cuestiones. Por un lado una concepción del orden de lo "racial" subyacía a la explicación de por qué el misionero es una persona apta para el trabajo en la forestación; cuestiones que hacen referencia a la sangre fuerte, producto de la mezcla de nacionalidades de los ancestros. Esta mezcla de "orígenes" es valorizada de forma positiva; gracias a la misma, gracias a la mezcla de "razas" el misionero es fuerte. El componente identitario emerge a partir de una interpretación de la biología, pero al valorizarse positivamente, la sangre es fuerte por la mezcla de varios orígenes; lejos está de aquella interpretación efectuada por contratistas y patrón, en la cual se construye la noción de fuerza, pero desde la noción de una naturaleza animal, distinta a la humana.

Por otro, debemos agregar la exaltación de una "una masculinidad" que aparecería de manera más intensa en los misioneros que en los trabajadores locales. El misionero es más fuerte que el trabajador local porque es más hombre, "es más guapo". Esta masculinidad construye la noción de un cuerpo resistente a las condiciones adversas, implicadas en estas migraciones. Ser hombre misionero es ser hombre fuerte, aquí de vuelta "la fuerza" emerge como componente identitario, pero esta aparece valorizada desde el género.

El siguiente relato de un trabajador de 41 ańos, refleja algunas de estas cuestiones referidas a la masculinidad y la mezcla de "razas", como elementos identitarios importantes para explicar el buen desempeño de los misioneros como trabajadores forestales,

"En todos lados prefieren al misionero. Porque tiene una raza de indio. Muy fuerte. Muy corajudo. Y bastante aguante para el trabajo. Un misionero allá en Corrientes vale por 5 correntinos. Le supera en el trabajo. Muy guapo. No ve que acá en Misiones como es frontera con Brasil, Uruguay, Paraguay, no es que una persona, por ejemplo, tiene una raza añadida. A veces el padre brasilero, la mamá argentina. O sea el papá paraguayo y la mamá argentina, O sea uruguayo. Entonces con esa mezcla de sangre sale gente muy guapa y muy valiente. Hay una cruza de sangre que le da mucho 
talento, mucha vida. Porque ellos tienen una mezcla de un pais con el otro. Entonces se cría una persona con una sangre muy poderosa. Porque de la madre tiene un grupo y del padre tiene otro grupo. Ya nace con potencia. El hombre misionero es uno de los más guapos que hay".

Otro relato que explica al misionero como apto para la migración hacia la forestación es el de un joven trabajador forestal de 23 años;

"El entrerriano no puede hacer ese trabajo, no está acostumbrado a hacer trabajos duros, no tiene la fuerza, el entrerriano sabe plantar $y$ trabaja en fruta, no cortar árboles y cargar peso; la forestación es una tarea para hombres solamente; en cambio lo que hace un entrerriano también lo puede hacer una mujer, es por eso creo yo que hay tantos misioneros en los campamentos".

Por otra parte, debemos tener en cuenta que la actividad forestal ha sido una actividad productiva muy importante a lo largo de la historia de la provincia de Misiones. Esta situación, que implica a varias generaciones de trabajadores, nos conduce a prestar atención al proceso de socialización del trabajo de padres a hijos varones; a través del mismo, también es posible abordar la relación establecida entre masculinidad y actividad forestal. Los misioneros de la localidad estudiada, son preparados desde pequeños para desempeñarse en la actividad forestal y cuando se convierten en hombres se hallan en condiciones de migrar. Para migrar a la actividad forestal hay que ser "fuerte", atributo que tienen los hombres. Se pasa de niño a hombre una vez que se ha migrado, con la migración forestal se deja atrás la niñez, y se pasa a ser un hombre adulto.

En relación a esta socialización del trabajo que reciben los niños varones, un ex trabajador forestal de 67 años, relata:

"Cuando quedaron con 12, 13 años o 15, ellos pecharon para allá. Porque yo enseñé a mis hijos trabajar, no robar. Le di un modelo, desde chiquito, que ellos ganen el pan trabajando, no robando. No hacer mal para nadie. Entonces hoy yo tengo un orgullo, están para allá, no sé cómo están, pero yo le di un modelo".

Otro trabajador de 56 años, nos comenta al respecto,

“(..) Bueno, los primeros recibos trabajamos juntos, porque yo le quería dar experiencia para ellos. $Y$ después, más allá, nos separamos. Entonces cada cual trabajó individualmente. Los 
primeros recibos hicimos juntos. Porque le enseñé cómo ellos tenían que apilar la madera, como tenía que limpiarse, ordenar el trabajo. Entonces ellos tenian que tener una instrucción. De un tipo que tenga experiencia y después ellos, ya se fueron solos".

Aunque el trabajador misionero se explica a sí mismo como hombre fuerte, esto no significa que se desconozca como sujeto en situación de vulnerabilidad, lo cual muchas veces se expresa a través de tensiones con los contratistas que se traducen en una alta rotación de estos trabajadores; esta vulnerabilidad también puede visibilizarse en el relato de aquellos trabajadores que han sufrido accidentes laborales, que en algunos casos los obligaron a discontinuar con las migraciones.

El relato de un trabajador forestal, de 28 años, ilustra la cuestión de la alta rotación laboral: "Somos rotativos, rotativos; un día estamos acá con un patrón, otro día estamos allá... Algún día vamos a salir de esta esclavitud, si hay un puesto de trabajo en Misiones (.)”

Con respecto a las tensiones con patrones y contratistas el siguiente testimonio agrega:

"En forestal hubo un problema con el chileno, un contratista de la forestal argentina, el sinvergüenza no quiso pagar a la gente entonces se armó quilombo ahi, entonces bueno, arreglamos eso y nunca más fuimos con él. Tuvimos que ir a reclamar a la oficina de la empresa para que nos pague". (trabajador 26 años)

En relación a los accidentes laborales, el siguiente relato de un ex trabajador agrega:

"Yo empecé a laburar a los 13 años en el raleo (.) hace 7 años que no voy más a Entre Ríos porque me lastimé. Me lastimé la columna, me cai sentado en un tronco (.) a veces no puedo caminar mucho por el problema de la columna".

Estos relatos en los cuales aparece la dimensión de la vulnerabilidad laboral, dan cuenta de que si bien los misioneros se autoidentifican como aptos para desempeñarse en las tareas de forestación, ya que serían "fuertes" para realizar actividades pesadas, esto no implica una idea de "adaptación" y "aceptación", por parte de los trabajadores, a las condiciones laborales precarizadas presentes en los campamentos forestales. Dicha "adaptación" es un elemento explicativo presente en el relato de los empleadores, para legitimar mediante un discurso biologicista, la producción y reproducción 
de prácticas que les permiten sostener una tarea productiva, mediante la utilización de mano de obra barata.

\section{Conclusiones}

A lo largo de este artículo hemos tratado de demostrar que la movilidad de la mano de obra debe ser comprendida en relación a la articulación entre las características estructurales del mercado de trabajo y la interacción de los actores implicados en el mismo. En particular los trabajadores que analizamos participan en un mercado laboral segmentado (Piore 1983), ocupando los peores puestos de trabajo tanto en lo referente a la remuneración como a las condiciones laborales. De esta manera, como sugiere Lara Flores (2001), se desdibuja la idea de libertad absoluta de los desplazamientos laborales, debido a que ciertos sectores del mercado buscan atraer a determinados colectivos sociales en situación de vulnerabilidad, a los cuales se les asignan características estereotipadas que los "vuelven idóneos" para determinadas tareas.

En este sentido, la perspectiva utilizada, se diferencia de la concepción de mercado de trabajo planteada por la economía neoclásica, en donde prima la regulación natural de la oferta y la demanda, en la cual participan sujetos que actúan como seres totalmente racionales, maximizadores y plenamente conscientes de sus decisiones, no influenciados por valores o prácticas culturales. En relación con estos planteos, coincidimos con Giarraca (2000) y Mingo (2006) cuando afirman que el mercado laboral debe ser concebido como una construcción en la que participan activamente elementos simbólicos y organizativos, derivados de los distintos contextos culturales y sociales en los cuales se desarrolla la interacción entre los actores.

Desde esta perspectiva, un enfoque antropológico del mercado laboral resulta pertinente debido a que puede dar cuenta de las articulaciones que se producen entre las distintas dimensiones identitarias de los actores y su posición en la estructura social. Siguiendo esta línea, y sin desconocer la incidencia de factores estructurales, como son en este caso, la falta de empleo en la región de origen, el marco legal de estímulo a la actividad forestal y la exportación de pasta celulósica; creemos necesario posicionarnos metodológicamente desde la lógica de los actores para comprender la complejidad de la migración laboral estudiada.

Centrarnos en la interacción de los actores que integran el mercado laboral analizado nos permitió detectar cómo se construyen en torno a los migrantes una serie de estereotipos, que como sugieren Perrot y Preiswerk 
(1983), funcionan simplificando y generalizando al colectivo de los trabajadores misioneros, en este caso mediante la creación de una noción ficticia de sujeto idóneo para la ejecución de ciertas tareas. A su vez, los atributos identitarios que se utilizan para construir estos estereotipos deben ser comprendidos a partir de una noción de identidad de tipo relacional (Barth 1976) enmarcada en el contexto de relaciones desiguales de poder (Giménez 1994), lo cual implica para este estudio analizar conjuntamente los discursos de empleados y empleadores.

Patrones y contratistas, no solo consideran que los trabajadores misioneros poseen atributos naturales para realizar ciertas tareas productivas, sino que también expresan que los migrantes están naturalmente adaptados a condiciones de vida extremadamente pobres en sus lugares de procedencia, lo cual implica su capacidad de acomodación a condiciones laborales precarias.

De esa manera, las desigualdades de clase social entre empleadores y empleados quedan ocultas bajo la idea de que los atributos culturales de los trabajadores funcionan como una adaptación natural a condiciones de trabajo y de vida precarias. En este sentido la diversidad cultural cumple la función de enmascarar la desigualdad social, y a su vez justifica la segmentación étnica del mercado laboral propuesta por Wolf (1993). Asimismo, la actitud racista de los empleadores, a través de la utilización de términos como indio o animal a modo de sinónimos, empleada para justificar distintas situaciones de desigualdad, implica la existencia de un proceso de racialización de relaciones de clase (Margulis 1998).

Por otra parte, los trabajadores misioneros generan un estereotipo sobre sí mismos, en relación a su identidad laboral, a través de la interacción entre la identidad de género y la identidad étnica. Los migrantes se autoidentifican como sujetos fuertes capaces de llevar a cabo labores pesadas, esta fuerza sería resultado de los orígenes étnicos sumados a la masculinidad, que es expresada en términos de intensidad, en el sentido que propone La Cecla (2005), siendo el misionero "más hombre que los trabajadores locales" debido a que realiza tareas consideradas exclusivamente masculinas, mientras que el trabajo que realizan los entrerrianos es visto como realizable tanto por hombres como por mujeres.

Esta naturalización de aptitudes para realizar el trabajo forestal que aparece tanto desde el discurso de los trabajadores como desde el discurso de los empleadores; aunque adquiere diferentes significados y valorizaciones para los distintos actores implicados en el proceso migratorio, acaba siendo funcional al mismo fenómeno de segmentación laboral. De este modo, 
queda al descubierto cómo los discursos en torno a estos procesos, no solo constituyen una representación particular desde la visión de los actores, sino que también contribuyen a la reproducción y legitimación del orden establecido; en este sentido, como sugieren varios autores (Hanks 2005, Bricks 2005, Pizarro 2012), la clasificación de lo social mediante el lenguaje naturaliza relaciones de fuerza que pueden ser detectadas en los estereotipos raciales que emergen en el plano discursivo a través del análisis conversacional.

No obstante el análisis realizado en este artículo, queda pendiente en futuras investigaciones ampliar y profundizar los vínculos existentes entre los distintos aspectos identitarios que se ponen en juego en el caso estudiado, sobre todo en lo referente a la relación entre identidad de género e identidad laboral, que si bien aparecen como un elemento importante en los testimonios de los migrantes, aún no hemos podido dimensionar en profundidad sus implicancias. Sin embargo, más allá de las particularidades del caso presentado, queda clara la importancia que tiene el análisis a nivel de la interacción de los actores para comprender procesos migratorios vinculados a la esfera laboral, debido a que permite considerar cuestiones que no serían visibles considerando exclusivamente aspectos de tipo macrosocial, como es la legitimación de la precarización laboral a través de la construcción de estereotipos.

Por último a partir de la idea de pensar a la categoría de migrante como una dimensión que agudiza la desigualdad inherente a la posición de clase social en la que se insertan los sujetos estudiados, se abre la reflexión en torno a la noción de extranjero para aquellos estudios que abordan procesos migratorios internos, quedando al descubierto que la nacionalidad no es un criterio excluyente para construir la extranjería de los sujetos. De esta manera, queda pendiente una discusión que problematice cuáles son los elementos que intervienen en la construcción de esta alteridad radical y a su vez, funcional a los procesos de segmentación del mercado laboral en el cual participan los trabajadores migrantes.

Agradecimientos: Este artículo se vincula con el proyecto de investigación denominado "El trabajo migrante transitorio en el agro argentino", $\mathrm{N}^{\circ}$ 232. Dirigido por Guillermo Neiman y financiado por la Agencia Nacional de Promoción Científica y Tecnológica. 
Notas

1 La firma fomentó la creación de pequeñas empresas proveedoras de servicios de corte en las que podían insertarse los trabajadores despedidos. Muchos de estos contratistas eran ex-empleados de rango medio.

2 Se trata de postes de madera de distinto grosor y longitud utilizados como tutores de plantas y para estructuras de invernáculos.

3 Los planteos objetivistas o esencialistas de la identidad, postulan a la misma como un conjunto de rasgos que identifican a un grupo, los mismos serían inalterables con el paso del tiempo; por otra parte los enfoques subjetivistas plantean que la identidad es un sentimiento de autoidentificación o de pertenencia con un grupo o una comunidad, solo toma en cuenta el carácter subjetivo de la elección personal. Este último enfoque deja de lado el hecho de que las identidades se construyen en el seno de los procesos sociales y no se reducen a decisiones individuales.

4 Nombre que recibe el trabajador rural de la selva en la zona del Paraguay y las provincias de Argentina Corrientes y Misiones, el término de origen Guaraní proviene de la palabra española mensual, referida a la frecuencia del pago del salario. Desde fines del siglo XIX se establecieron en Paraguay y el noreste argentino plantaciones de yerba mate que impusieron regímenes de trabajo forzado en condiciones abiertamente esclavas. Los mensúes solían ser reclutados por contratistas en puestos ubicados en cercanías a los puertos fluviales y transportados a las plantaciones donde eran instalados en barracas inhabitables.

5 El estereotipo es el conjunto de rasgos que puede caracterizar a un grupo en su aspecto físico, mental y en su comportamiento (Sinisi: 1998).

6 Según Giménez (1994) la autoidentificación alude a aquellos procesos mediante los cuales los miembros de un grupo se identifican como parte de un colectivo, mientras que la heteroidentificación alude a los procesos mediante los cuales los miembros que no pertenecen a dicho grupo identifican a dicho colectivo.

\section{BiBLIOGRAFÍA}

Archenti, A. 2008. "Producciones identitarias y relaciones interculturales en el periurbano platense". Mundo Agrario 17: 21-43.

Archentti, A. y M. Tomás. 1997. "Identidades migrantes e inserción local en un contexto subrural". Actas del Congreso Nacional Pobres y Pobreza en la Sociedad Argentina, pp 10-25. Universidad Nacional de Quilmes, Buenos Aires.

Baranger, D. y G. Schiavoni. 2005 "El político y el censista. A propósito del Censo de ocupantes de Tierras privadas en Misiones". Actas del seminario internacional de población y sociedad (SEPOSAL), pp: 9-17. Salta.

Bardomas, S. y D. Díaz. 2007. El Trabajo en la Actividad Forestal en la Provincia de Entre Ríos. Mimeo. Buenos Aires.

Barth, F. 1976. Los Grupos Étnicos y sus Fronteras. Fondo de Cultura Económica, México D.F.

Bendini, M.; N. Streimberger y M. Radonich. 2012. "Emergencia de viejos temas en un contexto modernizado: Marco teórico metodológico en un estudio de migrantes estacionales al sur de Argentina”. Politica y sociedad 1: $141-161$.

Benencia, R. 2002. "La compleja trama del prejuicio. Aceptación y violencia sobre trabajadores bolivianos en la agricultura periférica de Buenos Aires". Actas de congreso Perspectivas comparadas de la migración: Francia - Argentina, pp: 20-34-. París. 
Briggs, Ch. 2005. "Communicability, Racial Discourse Analysis" Anthropology 34: 269-291.

Departamento de Dirección Forestal. 2010. Informe de la Industria Forestal. Ministerio de Agricultura Ganadería y Pesca, Buenos Aires.

Giarracca, N. 2000. Tucumanos y Tucumanas. Zafra, Trabajo, Migraciones e Identidad. La Colmena, Buenos Aires.

Giménez, G. 1994. "Apuntes para una teoría de la región y la identidad regional”. Estudios sobre las culturas contemporáneas, 6: 165-176.

Guber, R. 1991. El Salvaje Metropolitano. Reconstrucción del Conocimiento Social en el Trabajo de Campo. Legasa, Buenos Aires.

Hall, S. y P. Du Gay. 2003. Cuestiones de Identidad Cultural. Amorrortu, Buenos Aires.

Hanks, C. 2005. "Pierre Bourdieu and the Practices of Language". Annual Review Anthropology 34: 67-83.

La Cecla, F. 2005. Machos. Sin ánimos de ofender. Siglo XXI, Buenos Aires.

Lara Flores, S. 2001. "Análisis del mercado de trabajo rural en México, en un contexto de flexibilización”. En ¿Una Nueva Ruralidad en América Latina?, editado por N. Giarraca, pp.: 363-380. CLACSO, Buenos Aires.

Mauss, M. 1936. "Les techniques du corps". Journal de Psychologie. 32: pp: 365386.

Margulis, M. 1998. La Segregación Negada. Cultura y Discriminación Social. Biblos, Buenos Aires.

Maxwell, J. 1996. Qualitative research researhc designe. An interactive approach. Thousand Oaks, Sage, California.

Mingo, E. 2006. "Estrategias laborales de las mujeres asalariadas en el sector primario. El caso de las trabajadoras del Valle de Uco. Provincia de Mendoza. Argentina”. Actas del VII congreso latinoamericano de sociología rural, pp: 20-32. Quito.

Neiman, G. 2009. Estudio Exploratorio y Propuesta Metodológica sobre Trabajadores Agrarios Temporarios. Ministerio de economía y producción, secretaría de agricultura, ganadería, pesca y alimentos, Proyecto de desarrollo de pequeños productores agropecuarios (PROINDER), Buenos Aires.

Neiman, G. 2010. "Los estudios sobre el trabajo agrario en la última década: una revisión para el caso argentino". Mundo Agrario 20: 1-19.

OIT. 1997. "No más árboles enganchados ni productores de viudas. Nuevo repertorio de recomendaciones prácticas para la protección de los 
trabajadores forestales y el medio ambiente". Revista de la OIT (organización Internacional del Trabajo), 21: 12-23.

Piore, M. 1983. "Notas para una teoría de la estratificación del Mercado de trabajo". En El Mercado de Trabajo: Teorias y Aplicaciones, compilado por L. Toharia, pp: 10-31: Alianza, Madrid.

Pizarro, C.; P. Fabro y M. Ferrero. 2011. "Los cortaderos de ladrillo como un lugar de trabajo para migrantes limítrofes. La importancia de ser boliviano”. Revista estudios del trabajo 4:119-148.

Pizarro, C. 2012. "El racismo en los discursos de los patrones argentinos sobre inmigrantes laborales bolivianos. Estudio de caso, en un lugar de trabajo en Córdoba, Argentina”. Convergencia 19: 225-285.

Perrot, D y Preiswerk, R. D. 1983. Etnocentrismo e Historia. Nueva imagen, México.

Quiroga, H. 1971. Cuentos de Amor, de Locura y de Muerte. Losada, Buenos Aires.

Schiavoni, G.; S. Bardomas y A. Alberti. 2012. "La ruta a Concordia: Migraciones y ciclos laborales de trabajadores forestales misioneros". Actas del V congreso del Grupo de estudios rurales y de desarrollo, pp: 1-18. Posadas, Misiones.

Schiavonni, G. 2010. "Empresas y ocupantes: dificultades para la institucionalización de un mercado de tierras en el NE de Misiones". En Territorio, poder e identidad en el agro argentino, compilado por O. Marí, G. Mateo y C. Valenzuela, pp: 235-248. Imago Mundi, Buenos Aires.

Sinisi, L. 1998. "Todavía están bajando del cerro. Condensaciones estigmatizantes de la alteridad en la cotidianidad escolar". Actas del I congreso Virtual de Arqueologia y Antropología. Disponible en http://www.naya.org.ar/congreso/ ponencia2-2.htm, acceso 03 de abril de 2013.

Tadeo, N. y P. Palacios. 2005. "Migraciones interzafra y dinámica de los mercados de trabajo". Actas del séptimo congreso nacional de estudios del trabajo, pp:125. Buenos Aires.

Vera, L.M. y R. Biasizo. 2009. Los agronegocios en el complejo forestal del nordeste de Entre Ríos (fines de los 50 a la actualidad). Actas de las VI Jornadas Interdisciplinarias de Estudios Agrarios y Agroindustriales, pp: 1223. Buenos Aires.

Wolf. E. 1993. Europa y la Gente sin Historia. Fondo de Cultura Económica, México. 